\author{
Military Technical College \\ Kobry El-Kobbah, \\ Cairo, Egypt.
}

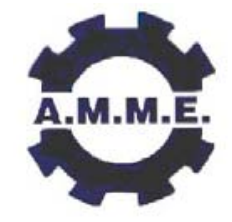

\title{
AN ASSESSMENT OF SEMI-ACTIVE SUSPENSION FOR PASSENGER CARS USING FULL CAR MODEL
}

\author{
IHSAN $^{*}$ S.I., FARIS ${ }^{* *}$ W.F. AND AHMADIAN ${ }^{* * *}$ M.
}

\begin{abstract}
Several control policies of F-car 7-DOF semiactive system, namely skyhook, groundhook and hybrid controls are presented, as a continuation of the previous work on Q-car 2-DOF and H-car 4-DOF models. Their ride comfort, suspension displacement and road-holding performances are analyzed and compared with passive system. The analysis covers both transient and steady state responses in time domain. The results show that the hybrid control policy yields better comfort than a passive suspension, without reducing the road-holding quality or increasing the suspension displacement for typical passenger cars. The hybrid control policy is also shown to be a better compromise between comfort, road-holding and suspension displacement than the skyhook and groundhook control policies.
\end{abstract}

\section{KEY WORDS}

Ride comfort, Full-car model, Semiactive system, Groundhook, Skyhook, Hybrid, Passive suspension system

\section{NOMENCLATURE}

$\begin{array}{ll}\text {-DOF } & \text { Degree-of-freedom } \\ \text { F-car } & \text { Full-car } \\ \text { H-car } & \text { Half-car } \\ m_{s} & \text { Sprung mass } \\ m_{u} & \text { Unsprung mass } \\ \text { PTP } & \text { Peak-to-Peak } \\ \text { Q-car } & \text { Quarter-car } \\ t_{s} & \text { Settling time } \\ \omega_{n} & \text { Natural Frequency }\end{array}$

* Graduate Student, Mechanical Engineering Department, International Islamic University Malaysia, Malaysia

** Assistant Professor, Mechanical and Mechatronics Engineering Departments, International Islamic University Malaysia, Malaysia

*** Professor, Mechanical Engineering Department, Virginia Polytechnic and State University, USA 


\section{INTRODUCTION}

Suspension systems are often used to control response of various rigid and flexible multi-body systems [1, 2] and the most commonly used suspension systems in vehicular applications, where they are used particularly to control the tire deflection or wheelhop for handling performance and vehicle body deflection and acceleration for passenger ride comfort [3].

Semiactive suspension systems continue to gain considerable attention in vehicle applications. This is due to its advantageous characteristics over passive system in overcoming the traditional conflict between vehicle safety and handling, and ride comfort, as well as its significantly less in complexity and power requirement than active suspension system [4-6].

Semiactive dampers can generally be classified based on their control scheme as either skyhook or groundhook. Hybrid control, which combines the effect of both skyhook and groundhook, has been shown to provide a compromise between the two while still performing better than the passive system $[7,8]$.

This work intended to look at the performance of these semiactive control policies and compare among themselves and the conventional passive system. The specific performance criteria of interest are the ride comfort, suspension displacement and road-holding responses. A full-car model is considered as an extension to the earlier analysis conducted on both quarter-car and half-car models $[9,10]$. Two analyses are conducted, namely the time-domain transient and steady state analyses.

\section{MODELING, DERIVATIONS AND ANALYSIS}

A full-car model used in this analysis is shown in Fig. 1. Notice that all the passive and semiactive control policies can be obtained from this single model. The system is said to be in hybrid control when the value of $\alpha$ is between 0 and 1 . For the purpose of this analysis, hybrid control is defined as $\alpha=0.5$. The equations of motion derived from the model are shown below:

$$
\begin{aligned}
& \mathrm{m}_{s} \ddot{\mathrm{x}}_{1}+\mathrm{k}_{s 1} Z_{1}+\mathrm{k}_{s 2} Z_{2}+\mathrm{k}_{s 3} Z_{3}+\mathrm{k}_{s 4} Z_{4}+\mathrm{c}_{\text {off } 1} \dot{Z}_{1}+\mathrm{c}_{\text {off } 2} \dot{Z}_{2}+\mathrm{c}_{\text {off } 3} \dot{Z}_{3} \\
& +\mathrm{c}_{\text {off } 4} \dot{Z}_{4}+\alpha\left(\mathrm{c}_{o n 1}-\mathrm{c}_{\text {off } 1}\right)\left(\dot{Z}_{1}+\dot{\mathrm{x}}_{4}\right)+\alpha\left(\mathrm{c}_{\text {on } 2}-\mathrm{c}_{\text {off } 2}\right)\left(\dot{Z}_{2}+\dot{\mathrm{x}}_{5}\right) \\
& +\alpha\left(\mathrm{c}_{o n 3}-\mathrm{c}_{o f f 3}\right)\left(\dot{Z}_{3}+\dot{\mathrm{x}}_{6}\right)+\alpha\left(\mathrm{c}_{o n 4}-\mathrm{c}_{o f f}\right)\left(\dot{Z}_{4}+\dot{\mathrm{x}}_{7}\right)=0 \\
& \mathrm{I}_{y y} \ddot{\mathrm{x}}_{2}+\mathrm{k}_{s 1} Z_{1} l_{f}-\mathrm{k}_{s 2} Z_{2} l_{r}-\mathrm{k}_{s 3} Z_{3} l_{r}+\mathrm{k}_{s 4} Z_{4} l_{f}+\mathrm{c}_{o f f l} \dot{Z}_{1} l_{f}-\mathrm{c}_{o f f} \dot{Z}_{2} l_{r}-\mathrm{c}_{o f f 3} \dot{Z}_{3} l_{r} \\
& +\mathrm{c}_{o f f} \dot{Z}_{4} l_{f}+\alpha\left(\mathrm{c}_{o n 1}-\mathrm{c}_{o f f 1}\right)\left(\dot{Z}_{1}+\dot{\mathrm{x}}_{4}\right) l_{f}-\alpha\left(\mathrm{c}_{o n 2}-\mathrm{c}_{\text {off } 2}\right)\left(\dot{Z}_{2}+\dot{\mathrm{x}}_{5}\right) l_{r} \\
& -\alpha\left(\mathrm{c}_{\text {on } 3}-\mathrm{c}_{\text {off } 3}\right)\left(\dot{Z}_{3}+\dot{\mathrm{x}}_{6}\right) l_{r}+\alpha\left(\mathrm{c}_{\text {on } 4}-\mathrm{c}_{\text {off } 4}\right)\left(\dot{Z}_{4}+\dot{\mathrm{x}}_{7}\right) l_{f}=0 \\
& \mathrm{I}_{x x} \ddot{\mathrm{x}}_{3}+\mathrm{k}_{s 1} Z_{1} a_{l f}+\mathrm{k}_{s 2} Z_{2} a_{l r}-\mathrm{k}_{s 3} Z_{3} a_{r r}-\mathrm{k}_{s 4} Z_{4} a_{r f}+\mathrm{c}_{o f f l} \dot{Z}_{1} a_{l f}+\mathrm{c}_{o f f} 2 \dot{Z}_{2} a_{l r}-\mathrm{c}_{o f f 3} \dot{Z}_{3} a_{r r} \\
& -\mathrm{c}_{o f f} 4 \dot{Z}_{4} a_{r f}+\alpha\left(\mathrm{c}_{o n 1}-\mathrm{c}_{o f f l}\right)\left(\dot{Z}_{1}+\dot{\mathrm{x}}_{4}\right) a_{l f}+\alpha\left(\mathrm{c}_{o n 2}-\mathrm{c}_{o f f 2}\right)\left(\dot{Z}_{2}+\dot{\mathrm{x}}_{5}\right) a_{l r} \\
& -\alpha\left(\mathrm{c}_{o n 3}-\mathrm{c}_{o f f}\right)\left(\dot{Z}_{3}+\dot{\mathrm{x}}_{6}\right) a_{r r}-\alpha\left(\mathrm{c}_{o n 4}-\mathrm{c}_{o f f}\right)\left(\dot{Z}_{4}+\dot{\mathrm{x}}_{7}\right) a_{r f}=0 \\
& \mathrm{~m}_{u 1} \ddot{\mathrm{x}}_{4}-\mathrm{k}_{s l} Z_{1}-\mathrm{c}_{o f f l} \dot{Z}_{1}+\mathrm{k}_{t 1}\left(\mathrm{x}_{4}-\mathrm{x}_{i n 1}\right)+(1-\alpha)\left(\mathrm{c}_{o n l}-\mathrm{c}_{o f f l}\right) \dot{\mathrm{x}}_{4}=0 \\
& \mathrm{~m}_{u 2} \ddot{\mathrm{x}}_{5}-\mathrm{k}_{s 2} Z_{2}-\mathrm{c}_{\text {off } 2} \dot{Z}_{2}+\mathrm{k}_{t 2}\left(\mathrm{x}_{5}-\mathrm{x}_{i n 2}\right)+(1-\alpha)\left(\mathrm{c}_{o n 2}-\mathrm{c}_{o f f 2}\right) \dot{\mathrm{x}}_{5}=0
\end{aligned}
$$




$$
\begin{aligned}
& \mathrm{m}_{u 3} \ddot{\mathrm{x}}_{6}-\mathrm{k}_{s 3} Z_{3}-\mathrm{c}_{\text {off } 3} \dot{Z}_{3}+\mathrm{k}_{t 3}\left(\mathrm{x}_{6}-\mathrm{x}_{i n 3}\right)+(1-\alpha)\left(\mathrm{c}_{o n 3}-\mathrm{c}_{\text {off } 3}\right) \dot{\mathrm{x}}_{6}=0 \\
& \mathrm{~m}_{u 4} \ddot{\mathrm{x}}_{7}-\mathrm{k}_{s 4} Z_{4}-\mathrm{c}_{o f f} 4 \dot{Z}_{4}+\mathrm{k}_{t 4}\left(\mathrm{x}_{7}-\mathrm{x}_{i n 4}\right)+(1-\alpha)\left(\mathrm{c}_{o n 4}-\mathrm{c}_{o f f} 4\right) \dot{\mathrm{x}}_{7}=0
\end{aligned}
$$

where,

$$
\begin{aligned}
& Z_{1}=\mathrm{x}_{1}+\mathrm{x}_{2} 1_{\mathrm{f}}+\mathrm{x}_{3} \mathrm{a}_{\mathrm{lf}}-\mathrm{x}_{4} \\
& Z_{2}=\mathrm{x}_{1}-\mathrm{x}_{2} 1_{\mathrm{r}}+\mathrm{x}_{3} \mathrm{a}_{\mathrm{lr}}-\mathrm{x}_{5} \\
& Z_{3}=\mathrm{x}_{1}-\mathrm{x}_{2} 1_{\mathrm{r}}-\mathrm{x}_{3} \mathrm{a}_{\mathrm{rr}}-\mathrm{x}_{6} \\
& Z_{4}=\mathrm{x}_{1}+\mathrm{x}_{2} 1_{\mathrm{f}}-\mathrm{x}_{3} \mathrm{a}_{\mathrm{rf}}-\mathrm{x}_{7}
\end{aligned}
$$

These equations have been validated by comparing in frequency response to the results obtained by Blanchard [11]. Note that since the left and right systems for both front and rear share the same distance to the center or gravity and the same tire and suspension parameters, identical results are obtained and thus only one of the responses are shown. The same model parameters, which are typical for passenger vehicle, are used for every configuration. Typical semi-active damping coefficients are chosen using the relationships of $\mathrm{c}_{o n_{i}}=2.2 \mathrm{c}_{s}$ and $\mathrm{c}_{o f f_{i}}=0.2 \mathrm{c}_{s}$ [11]. Three types of inputs are used - heave $\left(x_{i n 1}=x_{i n 2}=x_{i n 3}=x_{i n 4}=x_{i n}\right)$, pitch $\left(x_{i n 1}=x_{i n 4}=x_{i n}, x_{i n 2}=x_{i n 3}=-x_{i n}\right)$, and roll $\left(x_{i n 1}=x_{i n 2}=x_{i n}, x_{i n 3}=x_{i n 4}=-x_{i n}\right)$.

In the transient response analysis, the system is excited with a step input signal. Peakto-peak (PTP) value and settling time, $t_{s}$ values are noted for each control technique and compared. In the steady state response analysis, the system is excited with a sinusoidal input with input frequency is set to be equal to the natural frequencies of the system, $\omega_{n 1}, \omega_{n 2}, \omega_{n 3}, \omega_{n 4}, \omega_{n 5}, \omega_{n 6}$ and $\omega_{n 7}$. This is to simulate the worst case scenario at which resonances occur.

\section{RESULTS AND DISCUSSION}

\section{Transient State Response}

Figure 2 shows that while groundhook significantly improves the PTP response, the settling time of the response is significantly higher. Skyhook control improves settling times in all cases while the PTP are improved except in the case of vertical acceleration in pitch input. Hybrid control improves the PTP in all while the settling time in some cases is slightly increased. The roll acceleration response is negligible in the heave and pitch input but is the only significant response in the roll input.

Figures 3 and 4 show that for the case of suspension and tire deflection responses, while the settling time is improved in skyhook control, the PTP response is higher than the passive system. On the other hand, in groundhook control, the PTP response is generally better than the passive but that comes at the expense of significantly increased in the settling time. While for the skyhook and groundhook controls, improvement in one aspect is clearly at the expense of the other, hybrid control significantly improve both criteria in all cases.

Generally, for peak-to-peak response, hybrid control policy turns out to give the best response in $m_{s}$ (vertical, pitch and roll acceleration) and suspension deflection responses for all input types. On the other hand, groundhook control gives the best 
responses for tire responses. For the settling time, $t_{s}$ skyhook control gives the best response to $m_{s}$ and suspension responses in heave and pitch inputs.

It is also noted that responses in groundhook system generally takes significantly longer time to settle. Even though in some cases, passive system gives the best response, it can be said that hybrid control provides the best compromise of response overall. Generally the front system gives higher responses than the rear system in all input types. Also vertical response is higher than pitch response in heave input case, while pitch response is higher in pitch input. The tire and suspension responses do not vary significantly in heave and pitch input. The settling time in roll input is generally lower than in other input types.

\section{Steady State Response}

A summary of the Peak-to-Peak value for each control technique and passive system for all input frequencies and input types, are presented in Figs. 5-6 for sprung mass vertical, pitch and roll angular acceleration responses, and Figs. 7-8 for front and rear suspension and Figs. 9-10 front and rear tire deflection responses. Only the highest response each for input frequency equal $m_{s}$ natural frequencies $\left(\omega_{\mathrm{n} 1}, \omega_{\mathrm{n} 2}\right.$ and $\left.\omega_{\mathrm{n} 3}\right)$ and input frequency equal $m_{u}$ natural frequencies $\left(\omega_{\mathrm{n} 4}, \omega_{\mathrm{n} 5}, \omega_{\mathrm{n} 6}\right.$ and $\left.\omega_{\mathrm{n} 7}\right)$ are shown.

In all steady state time-domain response observations, it can be said that except for some cases, generally skyhook control policy significantly improves performance of all responses $-m_{s}$ accelerations, and suspension and tire deflections when input frequency is equivalent to $m_{s}$ natural frequencies, $\omega_{\mathrm{n} 1}, \omega_{\mathrm{n} 2}$ and $\omega_{\mathrm{n} 3}$, while groundhook control policy significantly improves responses when input frequency is equivalent to $m_{u}$ natural frequencies, $\omega_{\mathrm{n} 4}, \omega_{\mathrm{n} 5}, \omega_{\mathrm{n} 6}$ and $\omega_{\mathrm{n} 7}$. However, their improvements are at the expense of the other. For example, responses in skyhook control policy are significantly higher relative to passive system when input frequency is equivalent to $m_{u}$ natural frequencies. Hybrid system can be considered as a compromise between the two semiactive systems, and generally performs better than passive system.

Comparing between front and rear system responses for suspension and tire deflections, generally in heave and pitch inputs, front suspension and tire give higher response, while no significant difference for roll input.

Comparing between different input types, generally vertical response is higher than pitch response in heave input case, while pitch response is higher in pitch input. Roll response is not significant in heave and pitch inputs, while vertical and pitch responses are not significant in roll input. Suspension and tire responses in heave and pitch inputs are generally similar in all input frequencies. Responses in roll input are lower at $m_{s}$ natural frequencies for all suspensions and tires, while at $m_{u}$ natural frequencies are generally similar to heave and pitch inputs.

\section{CONCLUSION}

Several control policies of F-car 7-DOF semiactive system, namely skyhook, groundhook and hybrid controls were derived. Their ride comfort, suspension 
displacement and road-holding performances in time domain were analyzed and compared with passive system. The results show that the hybrid control policy yields better comfort than a passive suspension, without reducing the road-holding quality or increasing the suspension displacement for typical passenger cars. The hybrid control policy is also shown to be a better compromise between comfort, road-holding and suspension displacement than the skyhook and groundhook control policies.

\section{ACKNOWLEDGEMENT}

This work is funded by International Islamic University Malaysia (IIUM) Research Grant. A portion of this work was conducted while the author was at the Center for Vehicle Systems and Safety (CVeSS), Advanced Vehicle Dynamics Laboratory (AVDL), Virginia Tech., Blacksburg, VA as a visiting scholar.

\section{REFERENCES}

[1] Chalasani, R.M., "Ride Performance Potential of Active Suspension Systems - Part I: Simplified Analysis Based on a Quarter-Car Model," ASME Symposium on Simulation and Control of Ground Vehicles and Transportation Systems, AMD-vol. 80, DSC-vol. 2, pp. 187-204, 1986.

[2] Chalasani, R.M., "Ride Performance Potential of Active Suspension Systems - Part II: Comprehensive Analysis Based on a Full-car Model", Proceedings of 1986 ASME Winter Annual Meeting, Los Angeles, CA, December 1986.

[3] Ahmadian, M., "Semiactive Control of Multiple Degree of Freedom Systems", Proceedings of 1997 ASME Design Engineering Technical Conferences, Sacramento, CA, September 1997.

[4] Carter, A.K., 'Transient Motion Control of Passive and Semiactive Damping for Vehicle Suspensions", Masters Thesis, Virginia Tech., July 1998.

[5] Barak, P., 'Passive versus Active and Semi-active Suspension from Theory to Application in North American Industry", SAE Technical Paper 922140, 1992.

[6] Koo, J.H., Goncalves, F.D. and Ahmadian, M., "Investigation of the response time of magnetorheological fluid dampers", Proceedings of SPIE 2004 Smart Structures and Materials/NDE, San Diego, CA, March 2004.

[7] Ahmadian, M., "A Hybrid Semiactive Control for Secondary Suspension Applications", Proceerings of $6^{\text {th }}$ ASME Symposium on Advanced Automotive Technologies, Dallas, TX, November 1997.

[8] Ahmadian, M. and Vahdati, N., " Transient dynamics of semiactive suspensions with hybrid control", Journal of Intelligent Material Systems and Structures, v 17, n 2, February, 2006, p 145-153.

[9] Ihsan, S.I., Faris, W.F. and Ahmadian, M., 'Analysis of Control Policies and Dynamic Response of a Q-car 2-DOF semi active system', In print, 2007.

[10] Ihsan, S.I., Faris, W.F. and Ahmadian, M., 'Heave and Pitching Analysis of Semiactive Systems', Submitted for publication, May 2007.

[11] Blancard, E.D., "On the Control Aspects of Semiactive Suspensions for Automobile Applications", Masters Thesis, Virginia Tech. June 2003. 


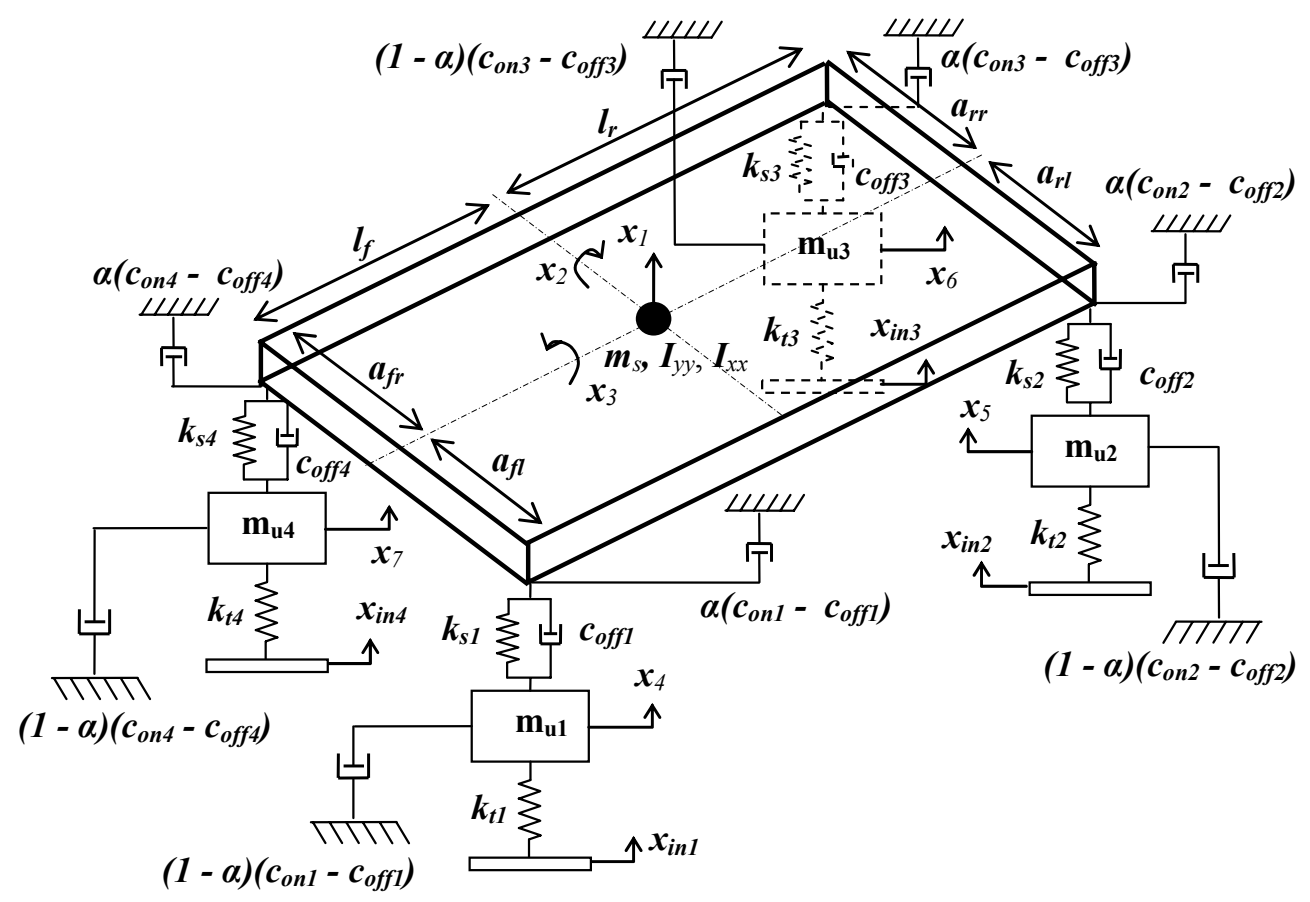

Fig. 1: Full-car 7-DOF model

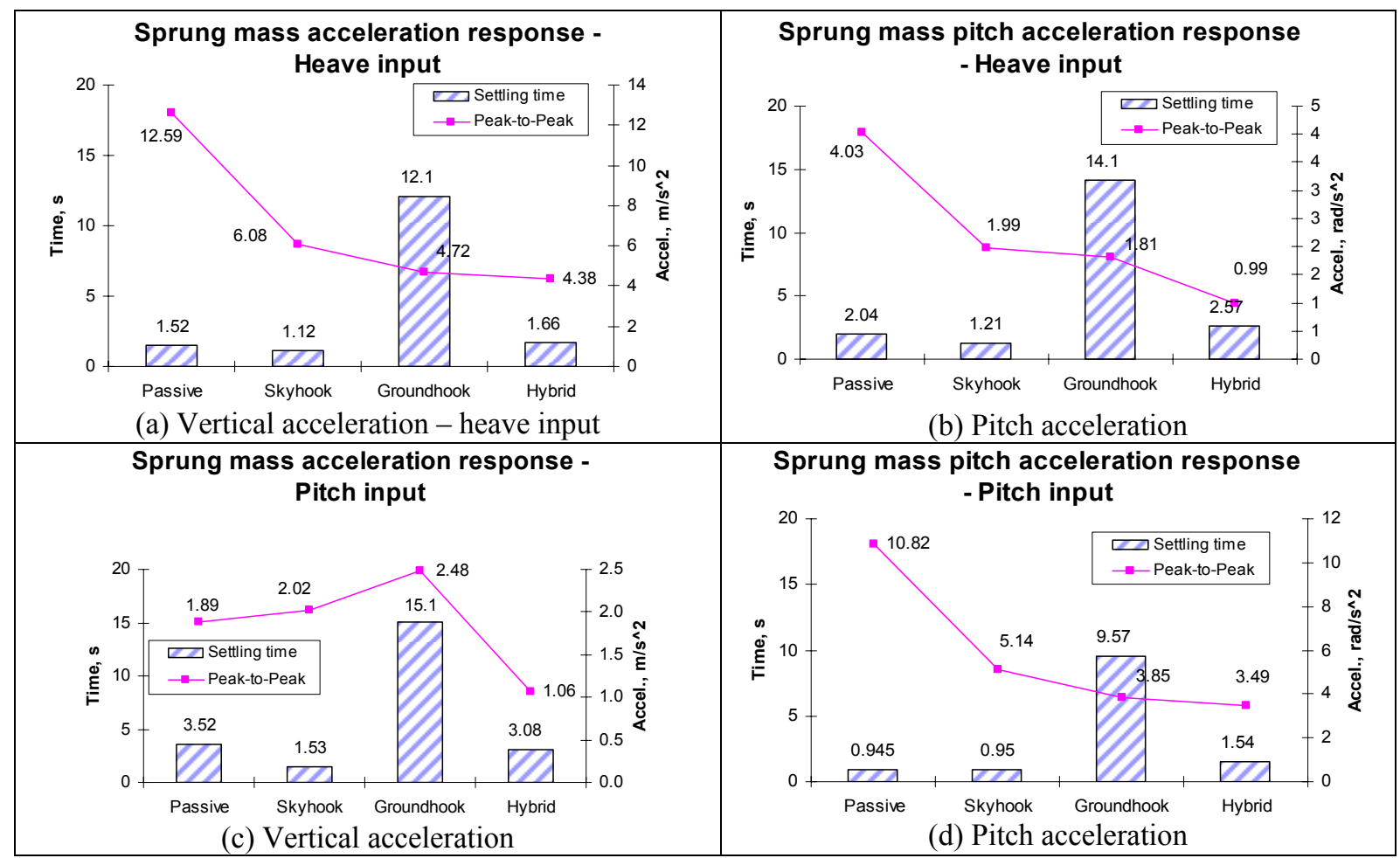




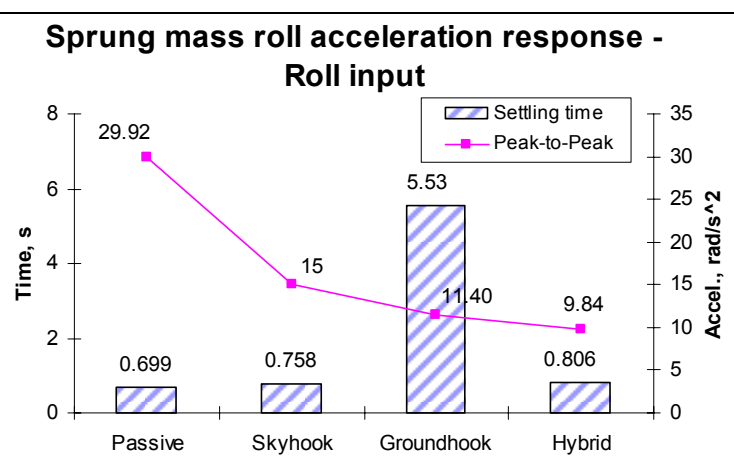

(e) Roll acceleration - roll input

Fig. 2: $m_{s}$ acceleration transient state response.

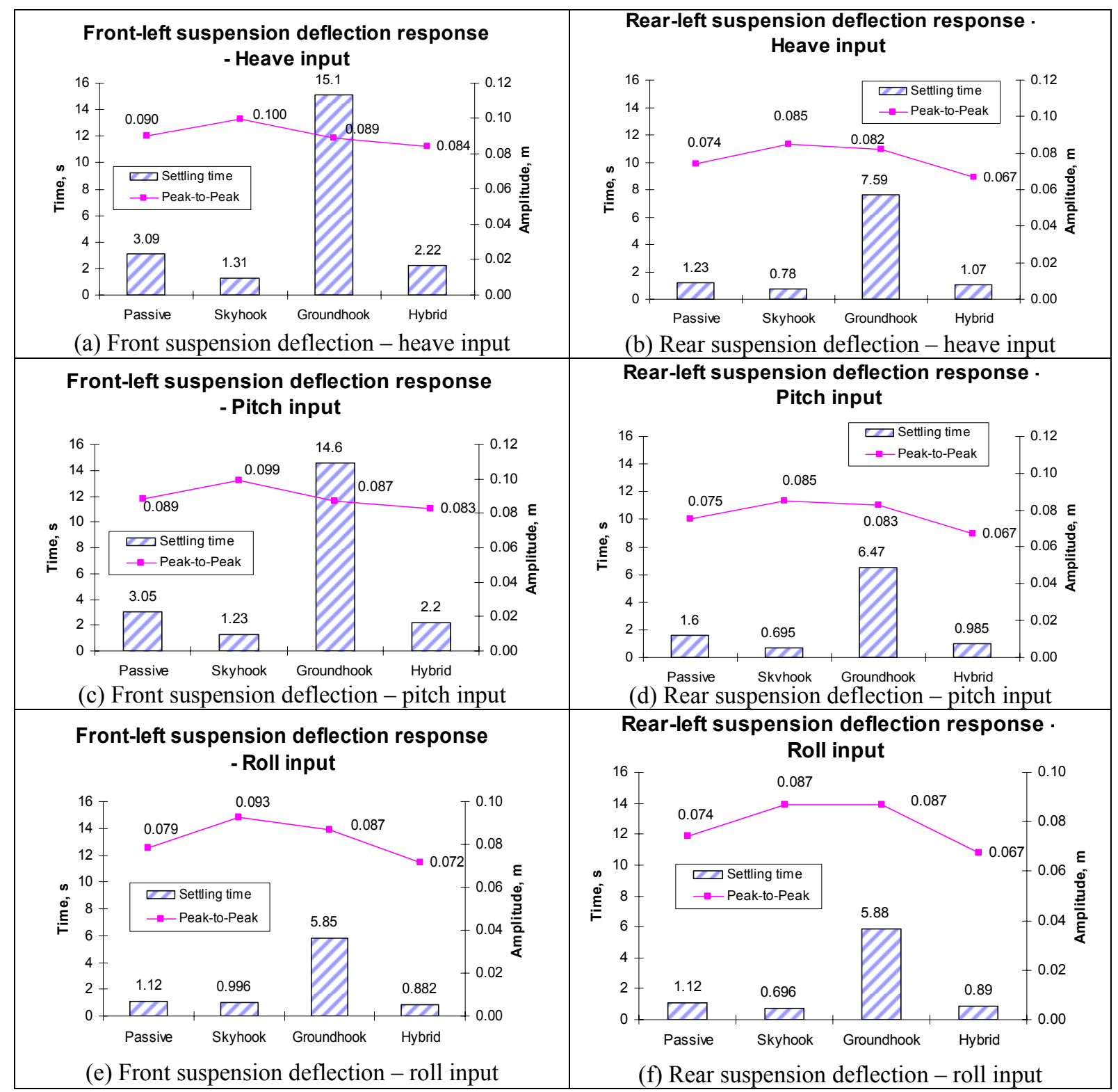

Fig. 3: Suspension deflection transient state response. 


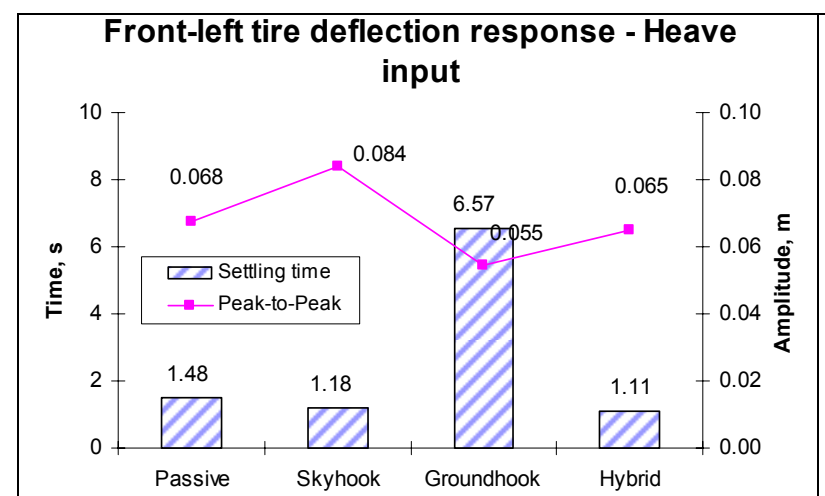

Rear-left tire deflection response - Heave input

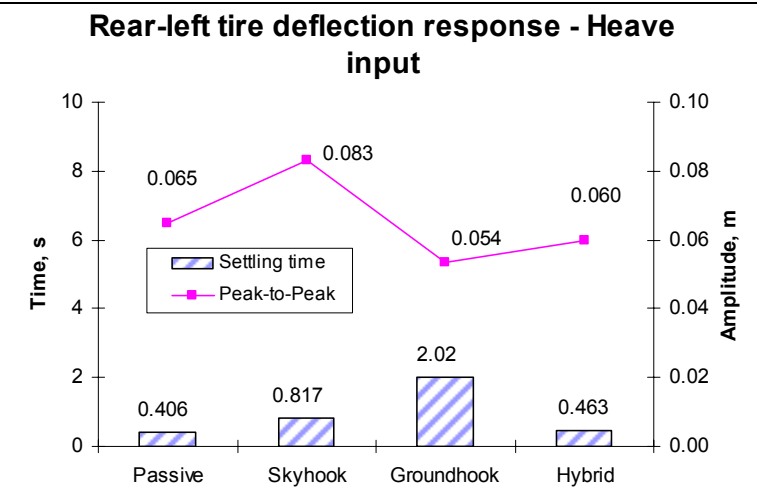

(a) Front tire deflection - heave input

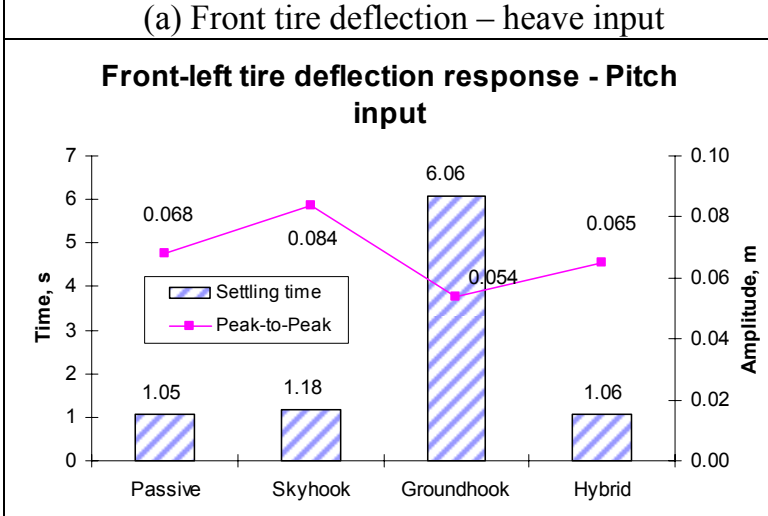

(c) Front tire deflection - pitch input

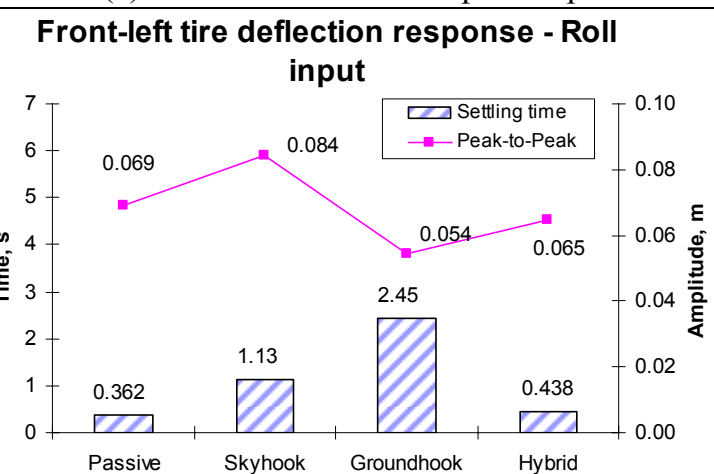

(e) Front tire deflection - roll input (b) Rear tire deflection - heave input

Rear-left tire deflection response - Pitch

input

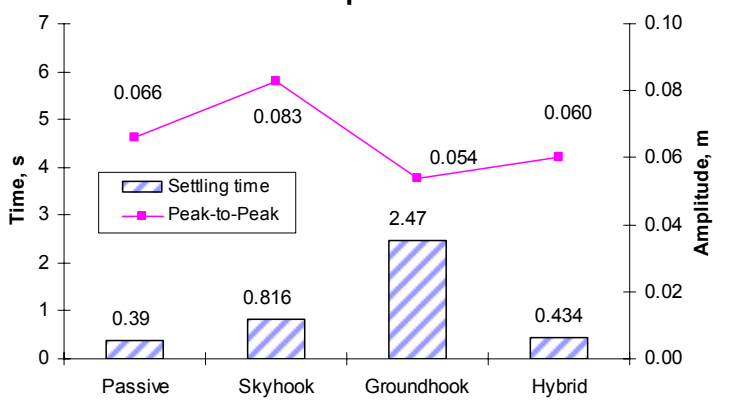

(d) Rear tire deflection - pitch input

Rear-left tire deflection response - Roll input

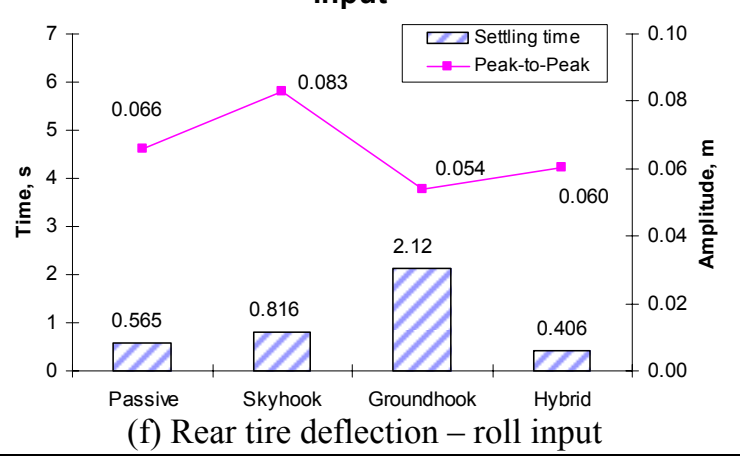

Fig. 4: Tire deflection transient state response. 


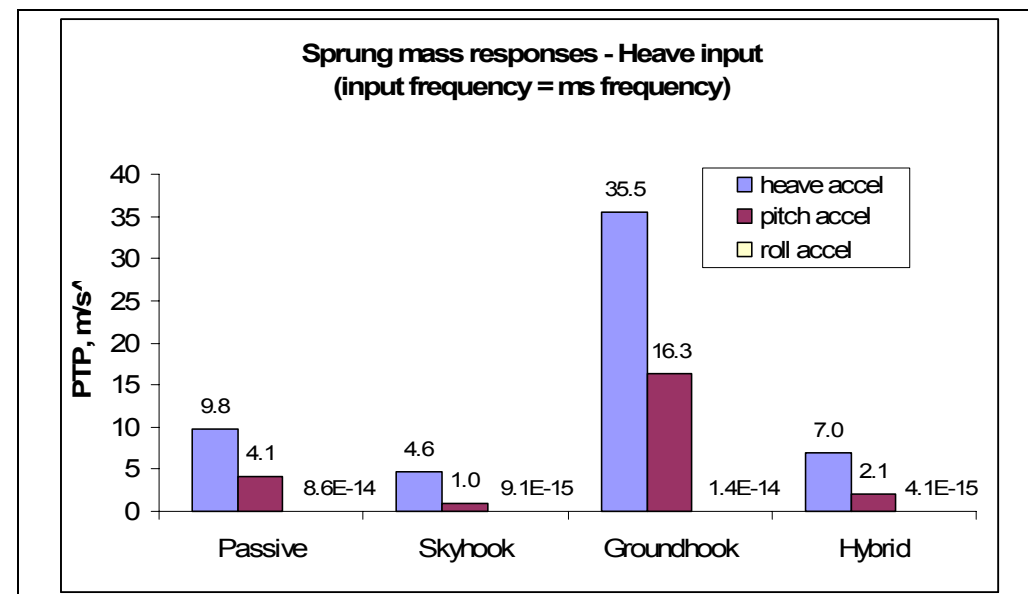

(a) Heave input

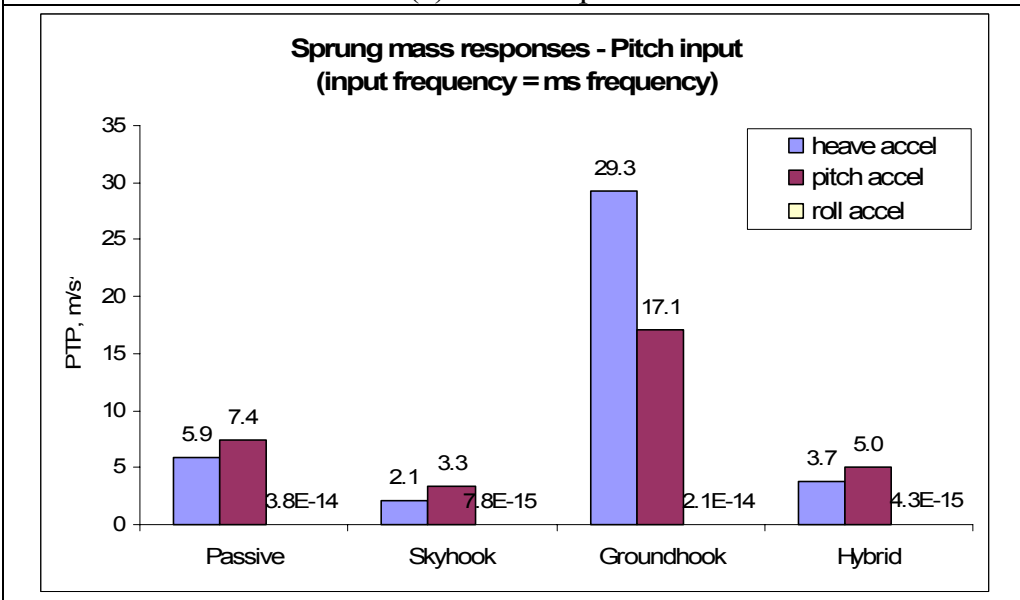

(b) Pitch input

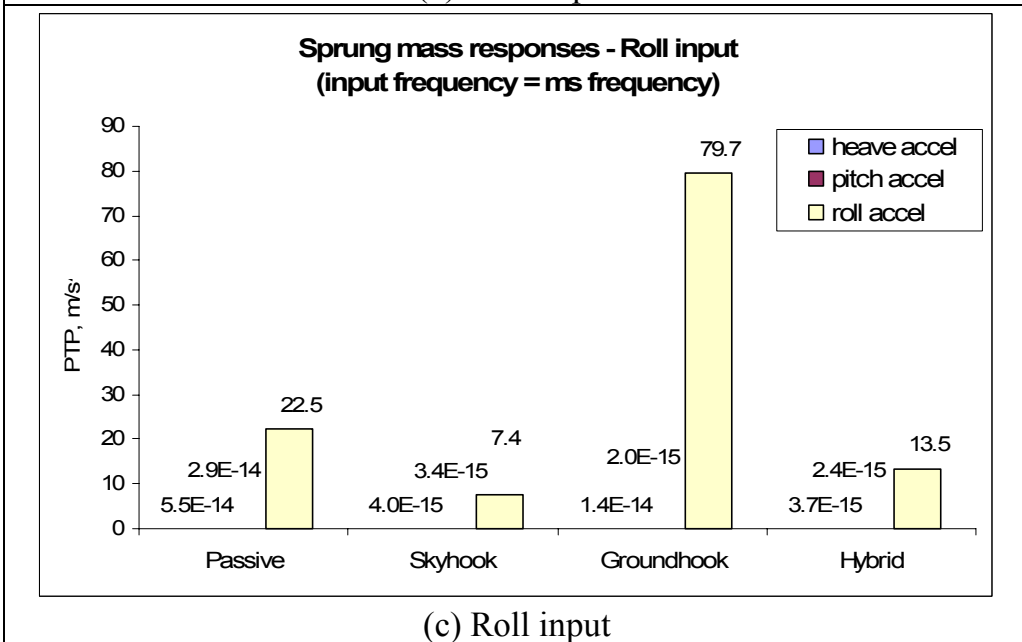

Fig. 5: $m_{s}$ acceleration steady state response $-\left(\omega_{\text {input }}=\omega_{\mathrm{ms}}\right)$. 


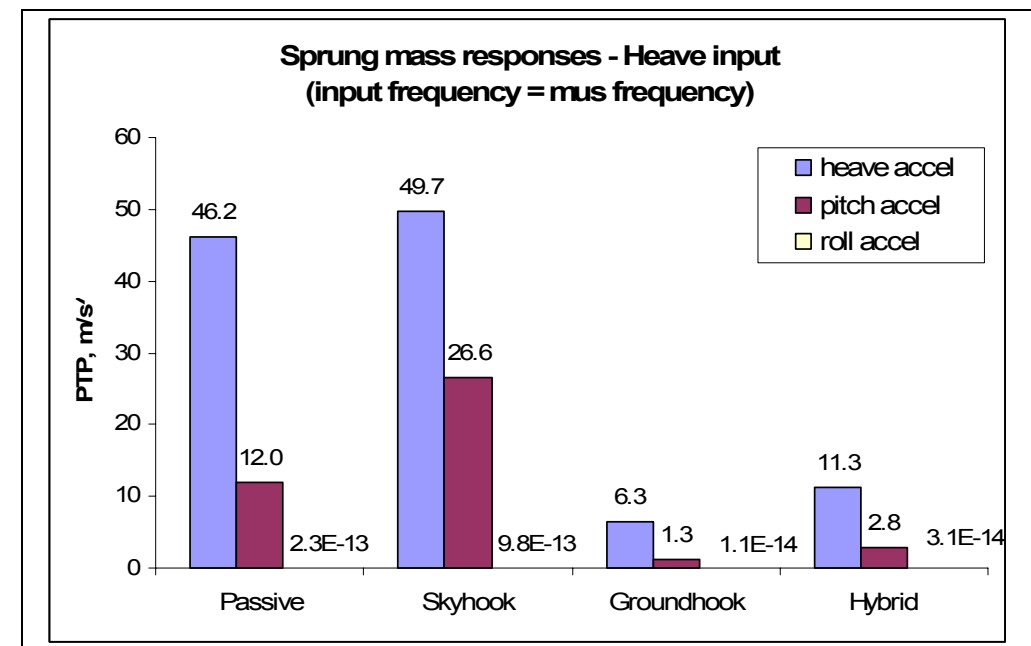

(a) Heave input

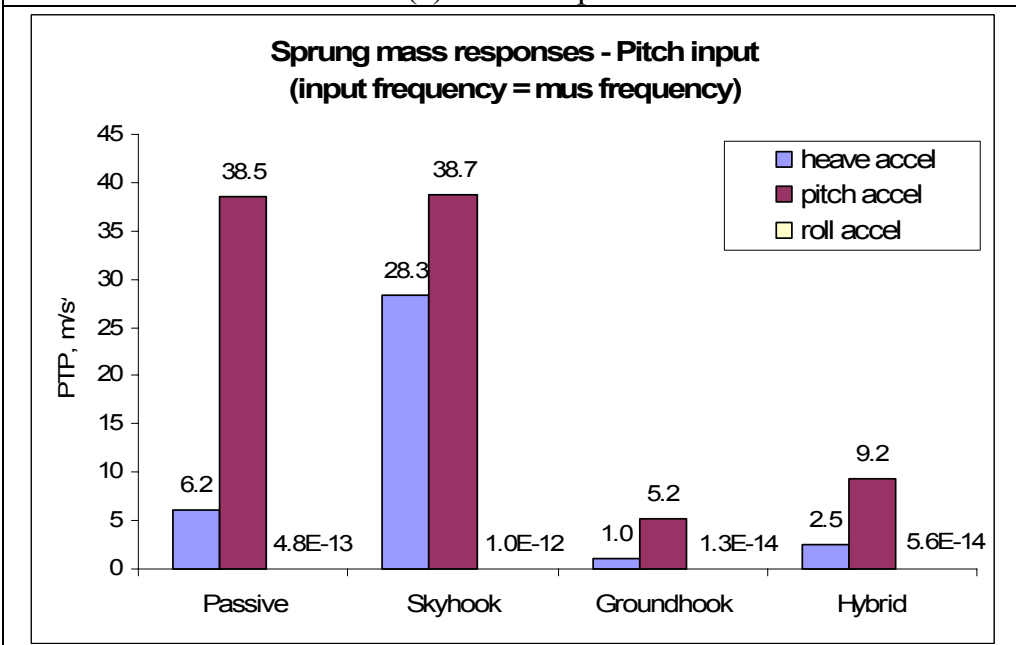

(b) Pitch input

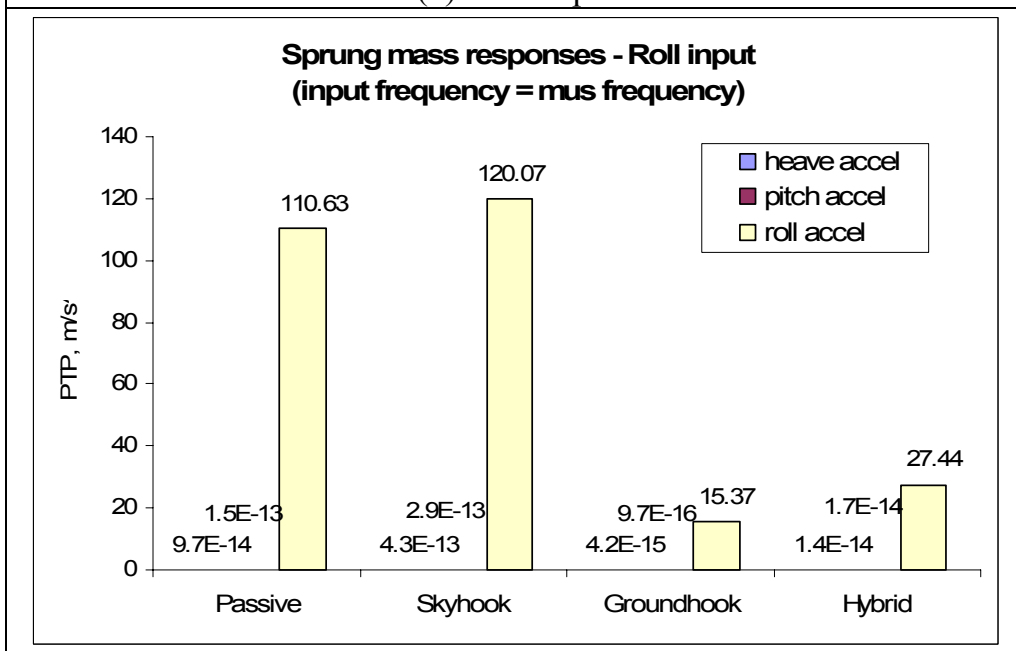

(c) Roll input

Fig. 6: $m_{s}$ acceleration steady state response $-\left(\omega_{\text {input }}=\omega_{\mathrm{mu}}\right)$. 


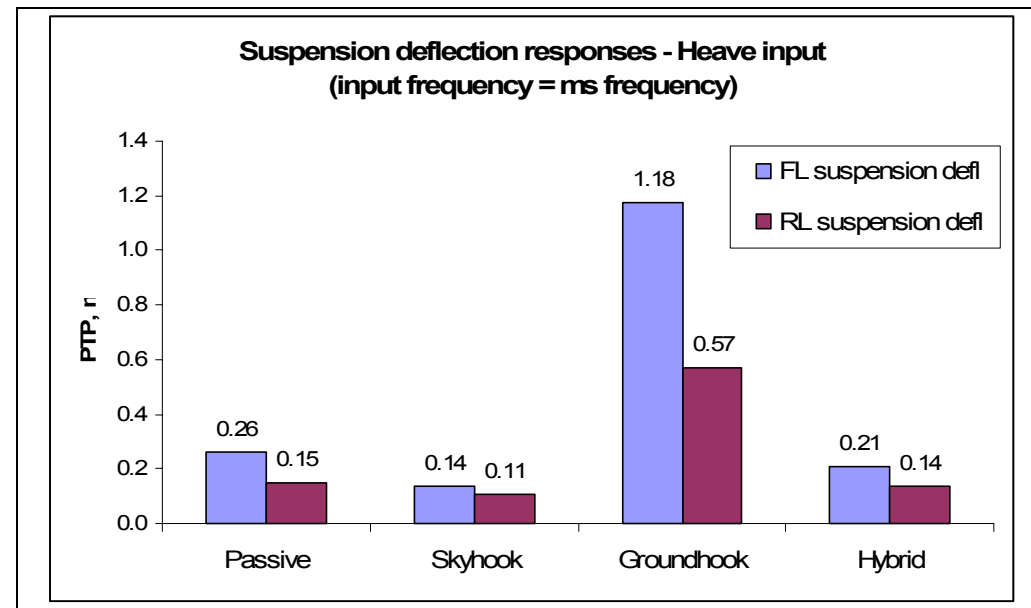

(a) Heave input

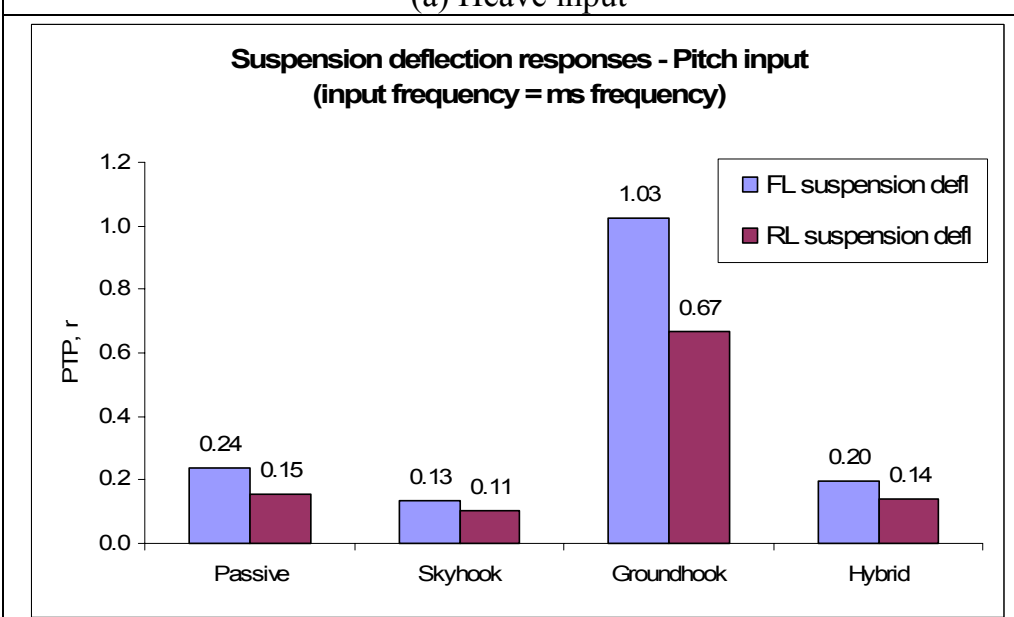

(b) Pitch input

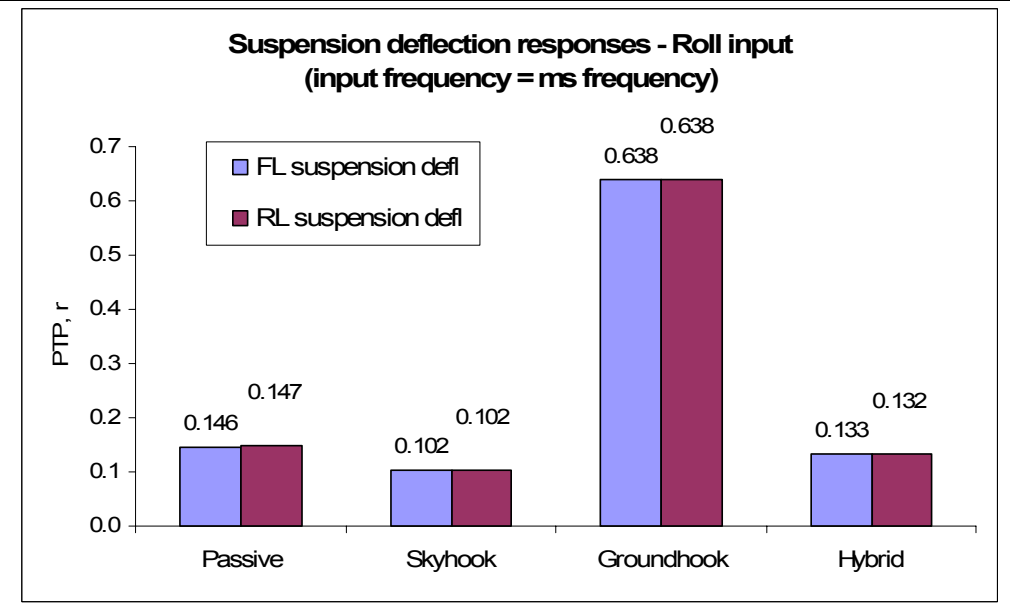

(c) Roll input

Fig. 7: Suspension deflection steady state response $-\left(\omega_{\text {input }}=\omega_{m s}\right)$. 


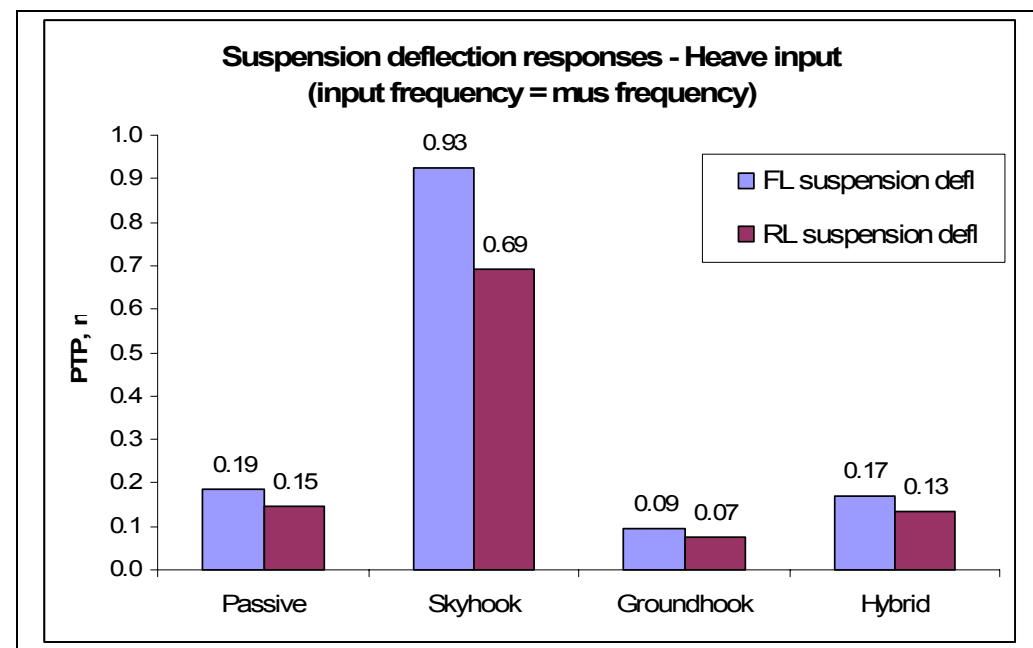

(a) Heave input

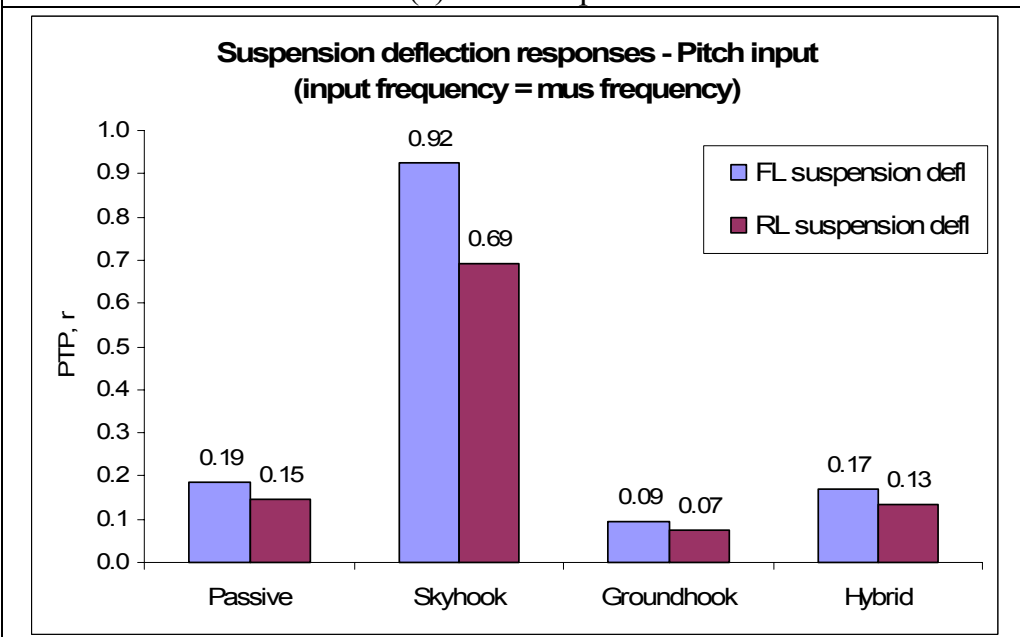

(b) Pitch input

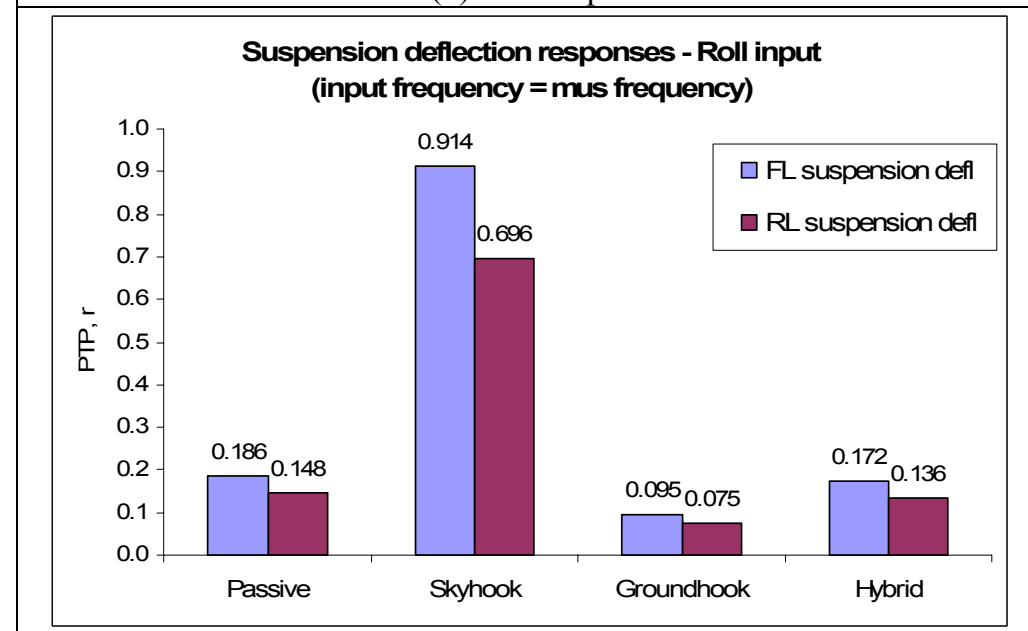

(c) Roll input

Fig. 8: Suspension deflection steady state response $-\left(\omega_{\text {input }}=\omega_{\mathrm{mu}}\right)$. 


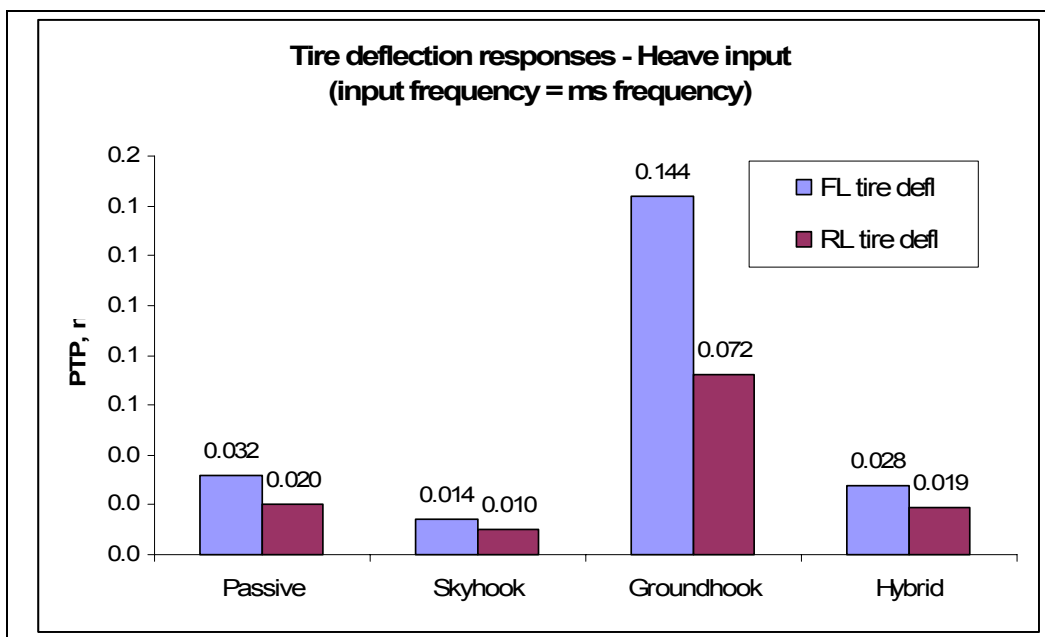

(a) Heave input

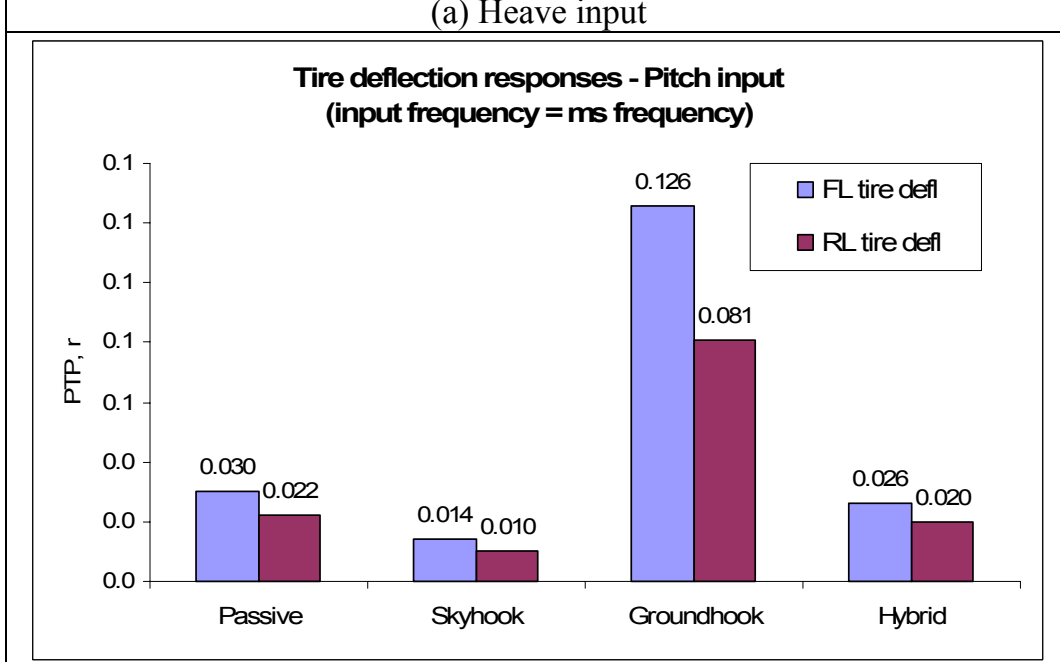

(b) Pitch input

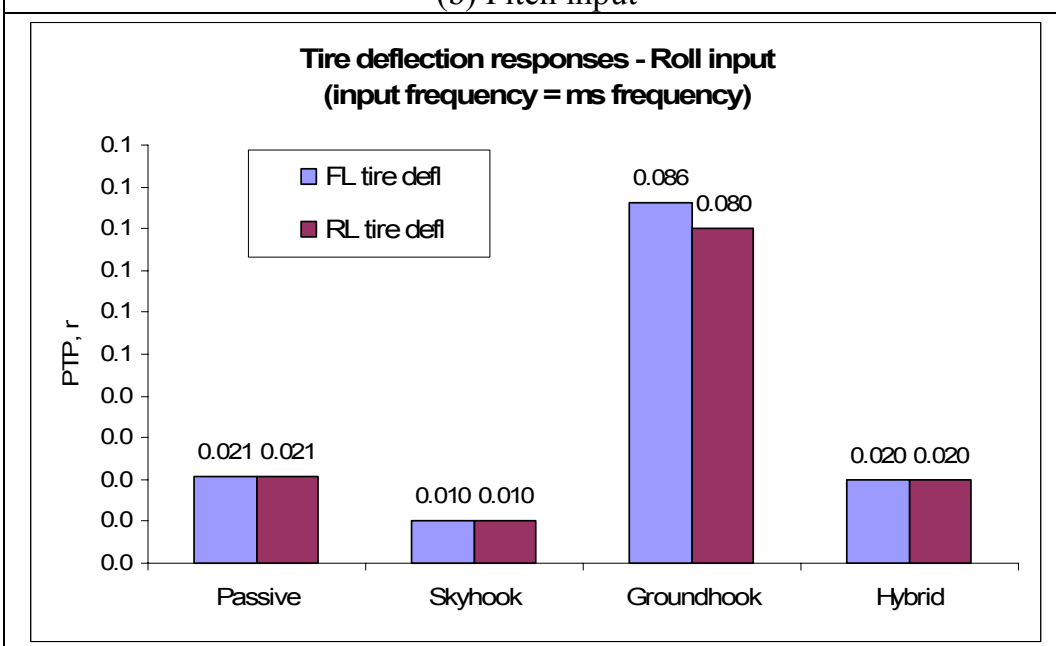

(c) Roll input

Fig. 9: Tire deflection steady state response $-\left(\omega_{\text {input }}=\omega_{\mathrm{ms}}\right)$. 


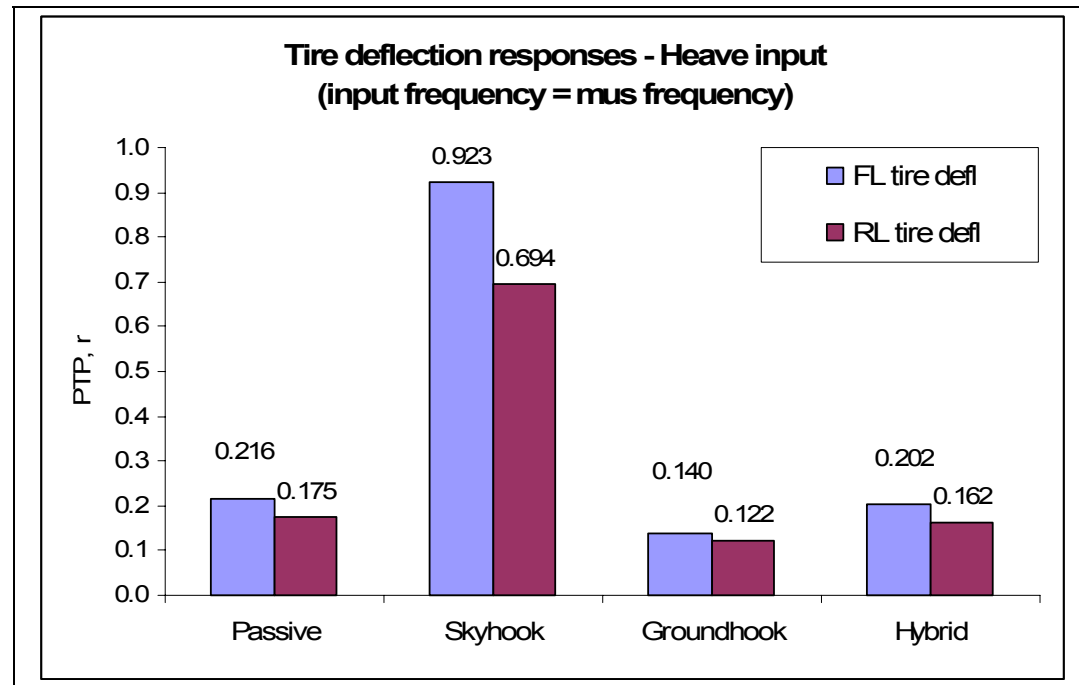

(a) Heave input

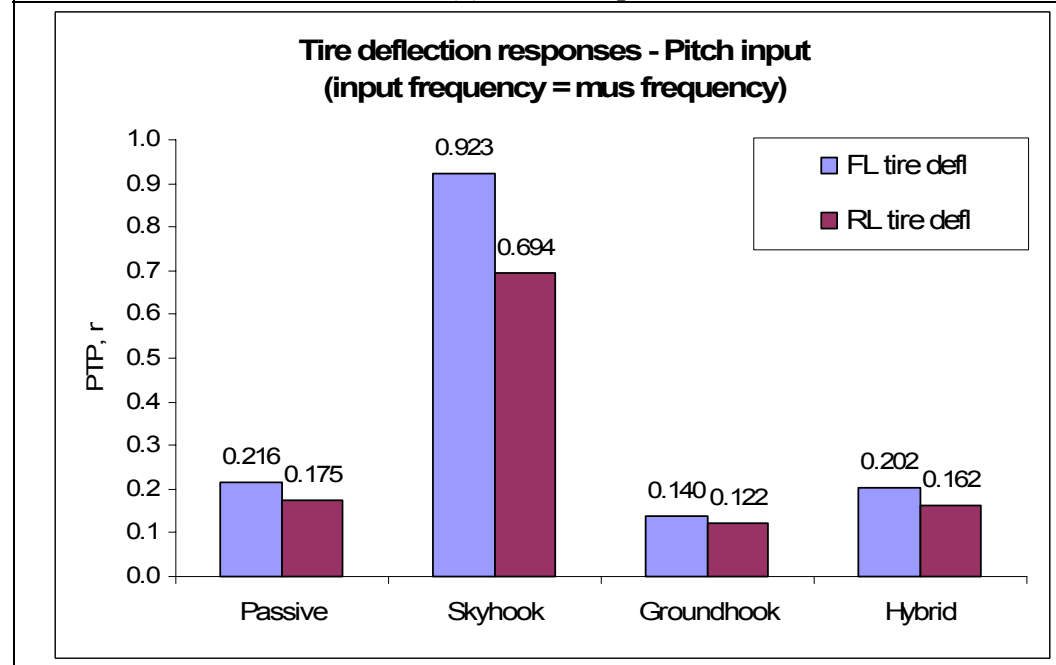

(b) Pitch input

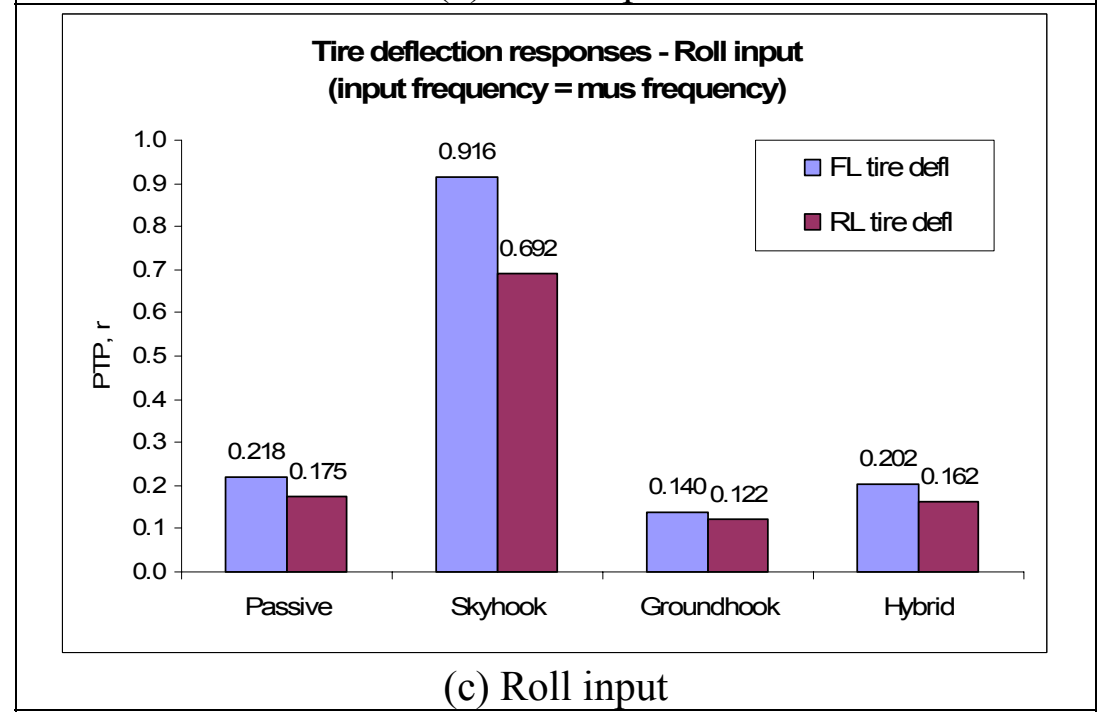

Fig. 10: Tire deflection steady state response $-\left(\omega_{\text {input }}=\omega_{\mathrm{mu}}\right)$. 